\title{
Capacitação e formação para o setor público e os modelos de escola de governo no Brasil
}

\author{
Milena de Senne Ranzini \\ Universidade Estadual de Campinas (Unicamp) \\ Newton Antonio Paciulli Bryan \\ Universidade Estadual de Campinas (Unicamp)
}

A capacitação e formação para o setor público ganharam destaque no Brasil, a partir de 1995, com os debates sobre a modernização das funções do Estado. Para promover maior capacidade de governo, foram criadas "escolas de governo" voltadas à qualificação de servidores públicos nos diversos entes federativos e poderes governamentais. A prestação dos serviços públicos não ficou restrita ao aparato governamental, assim como as experiências de profissionalização voltadas ao setor público, que também ocorreram em espaços não governamentais. Este artigo objetiva compreender os diferentes modelos de escolas de governo desenvolvidos no Brasil. Utilizamos a abordagem qualitativa, por meio de pesquisa bibliográfica e, baseando-se no ambiente onde estavam inseridos, classificamos os modelos identificados em: escolas de governo, instituições de ensino superior, universidades corporativas, organizações não governamentais e fundações partidárias. Concluímos que existe uma multiplicidade de organizações promovendo a profissionalização de servidores públicos, com intersecções variadas e diferenciados graus de atuação.

Palavras-chave: escola de governo, capacitação profissional, servidor público

\section{Capacitación y formación para el sector público y los modelos de escuelas de gobierno en Brasil}

La capacitación y formación para el sector público ganaron prominencia en Brasil, desde 1995 con las discusiones sobre la modernización de las funciones del Estado. Para promover una mayor capacidad de gobierno, se crearon "escuelas de gobierno" dirigidas a la calificación de los funcionarios públicos en diversas entidades federales y poderes públicos. La prestación de los servicios públicos no se limitó al aparato gubernamental, así como las experiencias de profesionalización centrada en el sector público, lo que también ocurrió en espacios no gubernamentales. Este artículo tiene como objetivo comprender los diferentes modelos de escuelas de gobierno desarrolladas en Brasil. Se utilizó un enfoque cualitativo,

[Artigo recebido em 20 de maio de 2015. Aprovado em 6 de março de 2017.] 
por medio de la literatura e, con base en el entorno en el que se insertaran, clasificamos los modelos identificados en: escuelas de gobierno, instituciones de educación superior, universidades corporativas, organizaciones no gubernamentales y fundaciones partidarias. Llegamos a la conclusión de que hay una multiplicidad de organizaciones que promueven la profesionalización de los funcionarios públicos, con variadas intersecciones y diferenciados grados de actividad.

Palabras clave: escuela de gobierno, capacitación profesional, servidor público

\section{Capacity building and training for the public sector and the school of government models in Brazil}

Capacity building and training for the public sector gained prominence in Brazil, from 1995 , on the discussions on the modernization of State functions. In order to promote greater government capacity, "schools of government" were created focused on the qualification of civil servants from various government entities and powers. The provision of public services was not restricted to the government apparatus as well as the professionalization experiences focused on the public sector, which also occurred in non-governmental spaces. This article aims to understand the different models of schools of government developed in Brazil. We used a qualitative approach, through bibliographical research and, based on the environment where they were inserted, we classified the models identified as: schools of governement, higher rducation institutions, corporate universities, non-governmental organizations and partisan foundations. We concluded that there is a variety of organizations promoting professionalization of civil servants, with varied intersections and differentiated degrees of performance.

Keywords: school of government, professional training, public servant 


\section{Introdução}

A capacitação e formação de servidores públicos é tema que vem ganhando maior expressividade no Brasil, principalmente após o advento das reformas do Estado, ocorridas na década de 1990. A nova configuração da função estatal demandou melhorias na prestação de serviços, gerando pressão para uma maior qualificação de servidores públicos. Para atender a estas demandas foram criadas "escolas de governo" nos diversos entes federativos e poderes governamentais. Ganharam expressividade também as experiências de profissionalização para o setor público estabelecidas fora dos espaços de governo, por meio de instituições de ensino superior, universidades corporativas, organizações não governamentais e fundações partidárias. O conceito de escola de governo admite uma multiplicidade de organizações, com experiências variadas e com aspectos diferentes, mas, com propósitos, muitas vezes, comuns.

Como objetivo principal deste artigo, buscamos identificar os variados modelos de escolas de governo desenvolvidos no Brasil, sistematizando-os por meio da análise do ambiente em que estão inseridos e descrevendo, de forma sintética, seu desenvolvimento histórico. Para isso, utilizamos como metodologia a pesquisa bibliográfica, procedendo à investigação de documentos legais, artigos, livros e revistas especializadas. Ao optarmos pela abordagem qualitativa, consideramos que as características investigadas, como ambiente onde se inserem, destinatários, tipos de vinculação institucional, fontes de financiamento etc., nos serviram à compreensão das diversas experiências de profissionalização do setor público. Apesar de os modelos de escola de governo terem sido delimitados neste texto, consideramos que as possibilidades existentes não se esgotam nos tipos aqui apresentados.

Afinal, o que é uma escola de governo? A diversidade de instituições abarcadas pela expressão faz com que seja necessário adotar o conceito mais adequado a cada um dos modelos. Tendo em vista que essas unidades se desenvolveram de forma assistemática no Brasil, Pacheco $(2000,2003)$ considera que o conceito seja bastante amplo e sua utilização imprecisa. Em sua análise, o termo vem sendo usado indistintamente por organizações públicas, privadas ou não governamentais, destinadas à formação de quadros, reciclagem de funcionários ou ainda fóruns de debate, especialmente para os poderes executivo e legislativo, nas três esferas de governo. Nogueira (2005) aponta que as escolas de governo se organizaram mediante iniciativas acadêmicas e não acadêmicas, governamentais e não governamentais, com e sem fins lucrativos. A dificuldade em relação à conceituação soma-se às diversas nomenclaturas utilizadas para designar estas unidades: Escola de Gestão Pública, Escola de Administração Pública, Escola do Serviço Público, Escola de Formação e Desenvolvimento de Servidores, 
Universidade Corporativa do Setor Público etc. A terminologia "escola de governo" foi consagrada pela Constituição Federal, por meio da Emenda Constitucional no 19 de 1998 (BRASIL, 1998). A Carta incluiu em seu texto que o Governo Federal, estados e Distrito Federal estavam obrigados a instituir e manter escolas de governo para a formação e aperfeiçoamento de servidores públicos. No entanto, Azevedo (2003) questiona se a escolha deste termo teria sido resultado de um gesto intencional, ponderado e refletido, ou seria obra do acaso e mera distração do Executivo, de deputados e senadores.

O Projeto de Emenda Constitucional no 173 (BRASIL, 1995a) não fazia referência à criação das escolas de governo, proposta que foi incluída apenas em 1997, durante a tramitação da emenda na Câmara dos Deputados. Ao analisar o processo de formulação, negociação e aprovação do referido dispositivo, Fernandes (2013) constatou que a capacitação de servidores não foi objeto de disputa em votação, tampouco polarizou posicionamentos, embora tenha sido objeto de discussão e negociação para o ajustamento do texto. A partir de então, as escolas de governo tornaram-se figura expressamente prevista no texto constitucional. Tendo em vista a ausência de normatização regulamentadora e mesmo de uma definição conceitual fundamentada e amplamente aceita, acabou-se gerando a possibilidade de organizações muito diversas serem estruturadas e reconhecidas como escolas de governo, incluindo todas aquelas que se autodenominam como tal e até mesmo as antigas áreas de treinamento. Como consequência, questões importantes como autonomia, personalidade jurídica adequada, subordinação, campo de ação, entre outros, não foram ainda objeto de discussão formal (MATOS, 2007; FERNANDES, 2013).

Diante da pluralidade de instituições englobadas pelo termo, partimos de uma sistematização dos diferentes tipos de experiências de profissionalização para o setor público, agrupando-as por seus aspectos semelhantes e diferenciando-as, quando necessário. O principal aspecto classificatório foi relativo ao ambiente em que a unidade está inserida e a que tipo de instituição está vinculada. O locus dá indicativos de quem são (ou podem ser) os destinatários, os focos e formas de atuação, fontes de financiamento, aspectos formais, legais, estruturais e outros elementos que compõem a concepção formativa destas organizações. Os modelos analisados foram:

a) Escolas de governo - ambiente: governamental: são organizações vinculadas direta ou indiretamente ao aparato estatal, financiadas e/ou mantidas por recursos públicos. Entre as principais referências deste modelo está a Enap - Escola Nacional de Administração Pública, primeira escola de governo instituída em âmbito nacional. A expansão das escolas governamentais demandou a criação de redes de 
apoio interinstitucional, com destaque para a criação da Rede Nacional de Escolas de Governo.

b) Instituições de Ensino Superior - ambiente: acadêmico: são instituições que promovem cursos de educação formal em administração pública e outros cursos do campo de públicas. Algumas escolas governamentais inserem-se nesse âmbito ao ofertarem cursos de pós-graduação lato sensu, de maneira independente.

c) Universidades Corporativas - ambiente: setor público/privado com fins lucrativos: em sua origem, as Universidades Corporativas foram unidades criadas dentro das empresas privadas com o objetivo de desenvolver competências e valorizar a cultura organizacional através de atividades de educação corporativa. Diante da expressiva expansão, ocorrida no Brasil a partir da década de 1990, diversos órgãos públicos passaram a adotar o modelo, adaptando-o às especificidades de capacitação profissional de servidores públicos.

d) Organizações não governamentais - ambiente: setor privado com ou sem fins lucrativos: são instituições que, mesmo não estando vinculadas ao aparato estatal, ofertam cursos voltados à temática pública para diversas categorias de agentes públicos, políticos e cidadãos.

e) Fundações partidárias - ambiente: partidos políticos (setor privado sem fins lucrativos): são fundações vinculadas a partidos políticos, objetivando promover a educação e formação política e cidadã para os militantes partidários e para a população, de forma geral.

A seguir, apresentamos uma análise de cada modelo, situando-os historicamente e apresentando seus principais aspectos.

\section{Escolas de governo}

Nos espaços governamentais, uma escola de governo está vinculada ao aparato estatal direta ou indiretamente, tendo suas atividades financiadas e/ou mantidas por recursos públicos. No Brasil, Carvalho (2005) aponta que a capacitação dos servidores públicos é desenvolvida nas cinco regiões do País por entes que vão desde escolas de governo com regime jurídico, infraestrutura e orçamentos próprios, até unidades de recursos humanos subordinadas a secretarias de administração e planejamento de governos estaduais ou municipais. No poder executivo, algumas escolas de governo são criadas para atuar de forma setorial, nas áreas de saúde, educação etc. Algumas instituições possuem focos de atuação mais específicos, como a formação de carreiras nas áreas de gestão do Estado, enquanto outras buscam alcançar um público mais amplo, ofertando cursos de curta e média duração abertos a diversos atores. 
Na concepção de Pacheco (2003), duas características principais diferenciam as escolas de governo de outros órgãos que promovem capacitação para o setor público. Primeiramente, a unidade deve estar vinculada ao aparelho estatal, mesmo que seja parte da administração indireta, como uma autarquia ou fundação. Em segundo lugar, demandam o recebimento de recursos orçamentários para seu funcionamento, sendo financiadas ou mantidas pelo setor público. Como consequência, as escolas devem servir aos interesses públicos, colocando o foco nas prioridades de governo e na melhoria do desempenho dos agentes e das organizações públicas.

A autonomia das escolas de governo, os limites de sua atuação e seus objetivos devem estar vinculados aos objetivos governamentais, mas não podem somente servi-los. Embora entes contidos na estrutura estatal, Matos (2007) acredita que não poderiam ser escolas "do" governo, sem uma margem de autonomia e condições para fornecerem ao Estado um corpo de servidores preparados com visão multidisciplinar para atuar como uma massa crítica essencial para pensá-lo, não se descurando da legalidade e da ética. Segundo Azevedo (2003), não se trata de tornar o servidor um profissional da política, nem mesmo de privilegiar a política no currículo, no entanto, ao buscar a profissionalização do servidor público é necessário navegar por esses conteúdos. A palavra "governo", na expressão "escola de governo", equivale não à política, mas à administração pública, corresponde não à disputa pelo poder ou à condução do Estado, mas à gestão ou administração do aparelho de Estado, à prestação do serviço (ao) público.

Na definição de Matus (1997, 2006), uma escola de governo deve ser um espaço institucional onde os dirigentes públicos possam renovar seus conhecimentos, trocar suas experiências, desenvolver sua vocação técnica e política e também novas competências para governar de forma aprimorada. É um centro onde as equipes dirigentes poderão se aproximar dos mais complexos problemas para o exercício do governo em situações difusas, incertas e interativas, onde a criatividade, o conhecimento técnico e a habilidade política devem estar juntos para a qualificação do processo decisório em ambiente público e para obtenção de resultados necessários. Está inserida em um processo de governo que entrelaça três variáveis: projeto de governo, capacidade de governo e governabilidade. A baixa capacidade para governar manifesta-se na incapacidade de realizar o processamento tecnopolítico de boa qualidade dos problemas sociais relevantes. Para tentar equacionar essa questão, Matus propôs um modelo de escola de governo (ESCOLAG - Escuela de Gobierno) onde a qualificação dos quadros responsáveis pela condução da gestão pública pudesse ser capaz de viabilizar o aumento da capacidade de governo. 
Capacidade de Governo é uma capacidade de liderança, ponderada pela experiência e os conhecimentos em Ciências e Técnicas de Governo. É uma capacidade de condução ou direção que se acumula na pessoa do líder, em sua equipe de governo e na organização que dirige. Apoia-se no acervo de técnicas, métodos, destrezas e habilidades de um ator e sua equipe de governo requeridas para conduzir o processo social, dadas a governabilidade do sistema e o compromisso do projeto de governo. Capacidade de governo é sinônimo de perícia para realizar um projeto. O domínio de teorias, métodos e técnicas potentes de governo e planejamento são uma das variáveis mais importantes na determinação da capacidade de uma equipe de governo. Quando falamos de teorias, técnicas e métodos de governo e planejamento nos referimos, por conseguinte, a alterar ou melhorar a capacidade de governo (MATUS, 2006, p. 07).

O que diferencia a ESCOLAG de outros modelos é o foco na formação de dirigentes e de outros estratos responsáveis pela condução da gestão pública, através de disciplinas baseadas no conhecimento em ciências e técnicas de governo. Para Matus (2007), este é o espaço de preparação de atores para a análise estratégica de problemas quase-estruturados. Apesar de não identificarmos a existência de uma escola de governo estruturada nos moldes propostos pelo autor, os princípios deste modelo influenciam na organização dos programas de formação voltados à profissionalização de servidores públicos.

A formação voltada às carreiras de alto escalão da gestão do Estado foi o objetivo que orientou a instalação da primeira escola de governo brasileira em âmbito nacional. A Escola Nacional de Administração Pública (Enap) foi criada nos moldes do modelo francês de formação de carreiras, tanto no que se refere à concepção pedagógica e curricular dos cursos de formação, quanto em sua organização administrativa. Ao longo do tempo, a Enap diversificou seu foco de atuação e vem também promovendo as ações de capacitação dos servidores públicos da administração federal. Historicamente, o Departamento Administrativo do Serviço Público (DASP ${ }^{1}$ ) havia solicitado ao Ministério das Relações Exteriores um estudo sobre os modelos externos de escolas de formação de carreiras. O estudo, realizado pelo então Embaixador Sérgio Paulo Rouanet, gerou o "Relatório Rouanet", em 1982, o qual apresentou uma análise comparativa entre os modelos francês e alemão de formação de administradores públicos. A partir daí foram criadas as bases para a elaboração de diretrizes gerais para a implantação da Enap (ROUANET, 2005; SANTOS et al., 1995; BRASIL, 2006). A Escola foi inicialmente instituída como uma diretoria da Fundação

${ }^{1}$ O Departamento Administrativo do Serviço Público (DASP) foi instituído pela Constituição de 1937 e regulamentado através do Decreto-Lei ${ }^{\circ} 579$, em 30 de julho de 1938. O órgão foi extinto no dia 03 de setembro de 1986, através do Decreto no 93.211. 
Centro de Formação do Servidor Público (Funcep), vinculada ao DASP, e destinava-se a planejar, promover, coordenar e avaliar as atividades de formação, aperfeiçoamento e profissionalização do pessoal civil de nível superior da administração federal. Enquanto isso, as atividades de treinamento dos servidores civis federais ficaram a cargo do Centro de Desenvolvimento da Administração Pública (Cedam²), também vinculado à Funcep e criado no mesmo momento da Enap.

No ano de 1990, as funções de formação, capacitação e treinamento foram agrupadas e a Funcep passou a denominar-se Fundação Escola Nacional de Administração Pública (Enap ${ }^{3}$ ), com as funções de promover, elaborar e executar os programas de capacitação de recursos humanos para a administração pública federal e coordenar e supervisionar os programas de capacitação gerencial de pessoal civil desenvolvidos pelos servidores de seu quadro permanente. As atividades da Enap diversificaram ao longo do tempo e, segundo relatório gerencial (BRASIL, 2014b), a atuação da Escola vem sendo orientada para fortalecer a gestão dos órgãos da administração pública federal e tem como atividades-fim a formação e o aperfeiçoamento de servidores, o assessoramento aos órgãos em temas de gestão pública, o desenvolvimento de pesquisas e publicações e a atuação em redes que apoiam a formação de agentes públicos.

A Enap teve importante papel na expansão das escolas de governo no País, pois, além de estabelecer um modelo de referência, fortaleceu as ações de formação e capacitação de servidores e estabeleceu conduta ativa na instalação da Rede Nacional de Escolas de Governo. A Rede foi estabelecida, em 2003, como uma articulação informal entre organizações públicas, não havendo mecanismos legais que regulassem seu funcionamento. Segundo Carvalho (2012), essa Rede é a articulação mais ampliada de organizações de caráter governamental interessadas na qualificação de agentes públicos. Assim, há um enorme grau de heterogeneidade interna abrangendo tanto entidades muito bem estruturadas, com ampla experiência no campo formativo e oferta formativa constante, quanto instituições em fase de consolidação, apresentando-se, muitas vezes, mais como demandantes das ofertas existentes das demais organizações. Os diferentes formatos jurídicos e de arquitetura organizacional também condicionam maiores ou menores possibilidades de participação e adesão por parte dos órgãos envolvidos. Desde então, algumas redes setoriais vêm se formando, agregando instituições de acordo com interesses comuns, áreas de atuação e tipos de vinculação. O objetivo

\footnotetext{
2 A Escola Nacional de Administração Pública (Enap) e o Centro de Desenvolvimento da Administração Pública (Cedam) foram instituídos pelo Decreto no 93.277, de 19 de Setembro de 1986.

${ }^{3}$ Através da Lei no 8.140, de 28 de dezembro de 1990.
} 
inicial tem sido promover a troca de informações e experiências entre as escolas participantes, mas há perspectivas de uma atuação mais efetiva das redes.

Uma escola de governo inserida no aparato estatal não é um fim em si mesma, possui autonomia relativa e deve vincular suas ações ao planejamento organizacional. Estas unidades podem ser caracterizadas por aspectos práticos, como as formas de vinculação ou financiamento, ou através de aspectos ideológicos, promovendo um constante debate sobre o Estado e a gestão de políticas públicas, superando a lógica de reprodução das concepções vigentes. Consideramos que sua atuação será estratégica se estiver vinculada ao planejamento institucional, promovendo cursos que auxiliem na qualificação dos agentes públicos responsáveis por proverem soluções para os problemas da sociedade.

\section{Instituições de ensino superior (IES)}

A organização e oferta de cursos de Administração Pública pelas instituições de ensino superior (IES) brasileiras faz com que o ambiente acadêmico seja reconhecido como um importante locus onde ocorre a profissionalização para o setor público. Historicamente, o desenvolvimento do ensino de administração pública vivenciou momentos de expansão e retração, sendo marcado por diversos ciclos e fases: auge e expansão nas décadas de 1950/1960; declínio na década de 1970; tímida retomada na década de 1980; e renascimento e forte desenvolvimento a partir de meados da década de 1990. A experiência norte-americana exerceu forte influência no estabelecimento deste ensino, pois, nos Estados Unidos, desenvolveram-se diversos programas de graduação e pós-graduação voltados tanto à administração pública quanto às políticas públicas.

No Brasil, a reforma administrativa ocorrida a partir de 1930 criou as bases para o ensino superior em administração pública. A partir de então, a evolução da disciplina foi segmentada em quatro ciclos principais (COELHO, 2006). O primeiro ciclo (1952-1965) foi marcado pela irradiação do ensino de graduação em Administração Pública no Brasil, tendo como precursora a Escola Brasileira de Administração Pública (Ebap), criada em 1952, vinculada à Fundação Getúlio Vargas (FGV). Destacou-se, nesse período, a cooperação com instituições acadêmicas norte-americanas e a sua influência na estruturação do currículo do primeiro curso, utilizado como modelo para a expansão dessa formação no País até o momento da regulamentação da profissão de Técnico em Administração, em 1965", e do estabelecimento do primeiro currículo

\footnotetext{
${ }^{4}$ A profissionalização da carreira administrativa ocorreu no cargo de Técnico em Administração, que, apesar do nome "técnico" estava vinculada à formação em nível superior. A Lei no. 4.769, de 09 de setembro de 1965, dispôs sobre o exercício da profissão de Técnico de Administração.
} 
mínimo da área de Administração, em 1966, uma década depois da instalação do primeiro curso (GAETANI, 1999; NiCOlinI, 2003; FARAH, 2011; COELHO, 2006; COELHO; NicolinI, 2011). O segundo ciclo (1966-1982) foi caracterizado por uma retração do ensino de administração pública, enfraquecido devido ao estabelecimento do currículo mínimo, em 1966, pelo mimetismo ocorrido com o currículo de administração de empresas e pela ênfase do ensino em instrumentos gerenciais voltados principalmente à aplicação nas empresas. Esses fatores provocaram grande queda do ensino de administração pública no País e, como consequência, a sua diminuição em outros espaços, como no ambiente governamental. O ensino de administração pública foi retomado timidamente após a Constituição de 1988, impulsionado pelo debate sobre o novo papel do Estado e pela ampliação do setor público no País, demarcando o terceiro ciclo (1983-1994). Coelho (2006) sugere que, a partir de 1995, o tema administração pública voltou à agenda nacional em função da redefinição do Estado e, assim, estaríamos vivendo um quarto ciclo, em que a visão sobre a área vem sendo ampliada, vislumbrando-se um campo maior de ensino. A transição democrática exerceu influência na expansão desse ensino e provocou uma revisão em seu currículo. O ensino não é mais exclusivo da área de administração pública e nem de disciplinas tradicionais, como a Ciência Política, assim, a multidisciplinaridade e interdisciplinaridade são reconhecidos como desafios à criação de uma identidade da disciplina de administração pública e da definição do campo de estudos de políticas públicas. Nesse cenário, a terminologia "campo de públicas" vem se apresentando como uma ideia-força que opõe "administração pública" à "administração de empresas" (privada), por razões não só epistemológicas, mas de gestão e de avaliação educacional (PIRES et al., 2014).

Campo de Públicas é uma expressão [...] que se volta para assuntos, temas, problemas e questões de interesse público, de bem-estar coletivo e de políticas públicas inclusivas, em uma renovada perspectiva republicana ao encarar as ações governamentais, dos movimentos da sociedade civil organizada e das interações entre governo e sociedade, na busca do desenvolvimento socioeconômico sustentável, em contexto de aprofundamento da democracia (PIRES et al., 2014, p. 112).

Apesar disso, a nomenclatura "administração pública" foi mantida no momento em que foram editadas as Diretrizes Curriculares Nacionais (DCNs) do respectivo curso de graduação, em $2014^{5}$. As diretrizes abrangem o campo multidisciplinar de investigação e atuação profissional voltado ao Estado, ao governo, à administração

\footnotetext{
${ }^{5}$ A Resolução no 01, de 13 de janeiro de 2014, instituiu as Diretrizes Curriculares Nacionais do curso de graduação em administração pública.
} 
pública e políticas públicas, à gestão pública, à gestão social e à gestão de políticas públicas. Segundo Pires et al. (2014), o desafio, a médio ou longo prazo, é que ocorra a mudança da nomenclatura das DCNs para "campo de públicas", traduzindo o arranjo multidisciplinar caracterizado por cursos que interpenetram diversas áreas de conhecimento.

Ao longo da história, os variados arranjos do Estado impactaram o desenvolvimento de cursos voltados à temática pública nas instituições de ensino superior (IES). No Brasil, encontram-se unidades acadêmicas atuando nos espaços governamentais, promovendo treinamentos e cursos, enquanto escolas de governo atuam no ambiente acadêmico, ofertando cursos de pós-graduação lato sensu, conferindo os respectivos graus acadêmicos. Além disso, muitos instrutores das escolas de governo são provenientes da academia, enquanto muitas universidades fazem parte da Rede Nacional de Escolas de Governo. Ambas as experiências de profissionalização para o setor público estão inter-relacionadas e influenciamse continuamente na sua oferta de ensino, existindo amplas possibilidades de interação e parceria.

\section{Universidades corporativas}

As universidades corporativas surgiram na estrutura interna das empresas privadas com o objetivo de promover ações de educação corporativa, buscando acelerar a aprendizagem e garantir a sobrevivência das organizações em um mercado globalizado cada vez mais competitivo. Surgiram nos Estados Unidos em meados da década de 1950 e introduziram-se no Brasil a partir de 1990. Ao ser adotada no setor público, esse modelo adaptou-se para atender às necessidades de capacitação de servidores públicos, todavia, baseando-se em seus princípios e características, consideramos que essas organizações sejam melhor adequadas às empresas públicas, em detrimento de outros órgãos governamentais.

Meister (1999) aponta que, entre 1950 e 1970, algumas empresas americanas formaram grupos para ensinar aos profissionais como fazer seu trabalho melhor. Essas infraestruturas educacionais proliferaram-se em todo o país e ficaram conhecidas como universidades, institutos ou faculdades corporativas. A suposição implícita era de que, se os trabalhadores adquirissem conhecimento suficiente por meio de metodologias de ensino na sala de aula, eles adquiririam novas qualificações para aperfeiçoar seu trabalho. Com o passar do tempo, um número crescente de empresas começou a perceber a necessidade de transferir o foco de seus esforços de treinamento e educação corporativa de eventos únicos em uma sala de aula para a criação de uma cultura de aprendizagem contínua, em que 
os funcionários aprendessem uns com os outros e compartilhassem inovações e melhores práticas com o objetivo de solucionar os problemas empresariais. A partir da década de 1990, as técnicas de aprendizagem obtiveram muita importância, pois as chances de uma organização mudar com sucesso passaram a depender da capacidade dos funcionários de aprender novos papéis, processos e habilidades. No Brasil, as universidades corporativas despontaram no final do século 20, levando as organizações a investirem na qualificação de seus profissionais e a se comprometerem com seu desenvolvimento contínuo. Assim como nos Estados Unidos, um novo ambiente empresarial, caracterizado por profundas mudanças e pela necessidade de respostas cada vez mais ágeis para garantir a sobrevivência das organizações, gerou um impacto significativo no perfil de gestores e profissionais que as empresas esperavam formar.

O conceito "universidade corporativa" foi criado tendo forte apelo mercadológico, porém, esse não é sinônimo de universidade acadêmica. A apropriação do termo "universidade", segundo Ramos (2001), foi uma opção das empresas para colocar a unidade de treinamento e desenvolvimento (T\&D) em um nível mais elevado, denotando uma seriedade de propósitos. O termo vem sendo adotado como reformulação do programa de treinamento das organizações sem, todavia, conferir-lhe atividades diferenciadoras, inovadoras e adequadas que justifiquem a mudança de nome. Isso tudo tem criado espaço para certa confusão quanto às diferenças entre uma universidade corporativa e uma área de T\&D, e até mesmo em relação às escolas de governo (ALPERSTEDT, 2001; MACK, 2008; ZAVATTI; BALDUÍNO, 2013).

A universidade corporativa não necessariamente apresenta-se como local físico, e sim como um processo. As dependências internas, externas ou virtuais de educação são um complemento estratégico para educar não apenas os funcionários, mas também parceiros, fornecedores, clientes e comunidade. Em muitos casos, estruturam-se como unidades de negócio da empresa, possuindo escopo e orçamento próprios. Essas unidades devem ajudar a organização a alcançar sua missão por intermédio da condução de atividades que cultivem a sabedoria, o conhecimento e a aprendizagem individual e organizacional. Como princípio fundamental, a criação e desenvolvimento das competências individuais e organizacionais é o método adotado para atingir os objetivos propostos. O corpo docente deixou de ser os acadêmicos renomados para ser os gerentes seniores que transmitem os conceitos que utilizam em suas vidas profissionais, aliados a exemplos práticos (MEISTER, 1999).

As organizações privadas tomaram a iniciativa de trazer as universidades para dentro das empresas, organizando os currículos e processos educacionais da melhor 
forma que se adequassem à realidade que estavam vivenciando. Paralelamente, os órgãos públicos também internalizaram estruturas de capacitação e formação por meio da instituição de escolas de governo. Por que, então, órgãos vinculados ao aparato estatal optaram por adotar o modelo das universidades corporativas? Qual a diferença entre os dois modelos?

Segundo Gaetani (1998), quase todos os avanços na área de administração se originam no âmbito empresarial, e a grande maioria das tecnologias gerenciais tem todas as condições de ser absorvida (total ou parcialmente) pelo setor público. Mas, para que esta tradução/transposição seja feita de forma produtiva e efetiva, o autor acredita que é importante atentar para a realidade do setor público, condicionada por uma série de fatores distintos do setor privado (rigidez legal, interferência política e um sistema próprio de punições e recompensas, entre outros). A desconsideração destas diferenciações prejudica a formatação dos programas de capacitação cada vez mais ofertados por provedores privados - e, em vez de instrumentalizar as instituições governamentais, reforça sua resistência e fechamento.

Em artigo publicado em 2002, Pacheco assinala que o governo necessitava de sua "escola corporativa de gestão" à semelhança das "universidades corporativas" desenvolvidas por grandes empresas privadas, reconhecidas como capazes de assegurar o alinhamento da capacitação aos valores e desafios estratégicos enfrentados pelas corporações. Consideramos que, no setor público, a existência de uma escola de governo, ou de uma universidade corporativa, esteja ligada, de forma estratégica, à necessária vinculação entre a oferta de capacitação e o planejamento organizacional. Porém, tendo em vista a ausência de um esclarecimento conceitual, ambos os termos perpetuaram-se para indicar experiências de profissionalização para o setor público. Uma diferença considerável seria em relação ao ambiente onde estão inseridos cada tipo de organização. Assim, enquanto uma escola de governo estaria vinculada aos órgãos da administração pública direta e indireta, supõe-se que uma universidade corporativa estaria vinculada a empresas públicas.

Em suma, mais do que um espaço físico, uma universidade corporativa representa um modelo de educação corporativa, baseado no ensino de competências para todos os profissionais e parceiros da organização. Elas estabeleceram a aprendizagem como uma estratégia de sobrevivência em um cenário cada vez mais competitivo. Diante disso, consideramos que a instalação dessas unidades seja mais adequada em empresas públicas do que em órgãos governamentais, tendo em vista que os pressupostos desse modelo foram desenvolvidos sobre preceitos privados. Não há impeditivos para que os órgãos inseridos no aparato estatal optem pelo modelo de universidade corporativa, desde que o adapte em seus espaços. 


\section{Organizações não governamentais}

As reformas administrativas empreendidas no Estado a partir 1995 trouxeram novas maneiras de gerir a coisa pública e variadas formas de provisão de serviços públicos. Verificamos que a oferta de serviços públicos de qualidade não se restringiu somente à melhoria do aparato estatal, mas esteve vinculada também ao padrão da oferta realizada pelas organizações não governamentais. Seguindo esta lógica, também foi ampliada a oferta de cursos com a temática pública, ocorrendo uma diversificação tanto dos tipos de organização que promovem as ações de capacitação quanto dos destinatários dos cursos. A demanda de preparação para atuar nos múltiplos espaços públicos vem aumentando gradativamente, ao passo que se reconheceram limitações na qualificação dos agentes. Nesse cenário, organizações não governamentais promovem cursos, consultorias, assessoria e planejamento para diversos órgãos e agentes públicos.

O foco das organizações não governamentais, na opinião de Nogueira (2005), seria a formação de pessoas capazes de pensar o setor público e de interferir direta ou indiretamente no espaço de governar, fossem elas gestores, juízes, parlamentares, governantes ou cidadãos e, quando fosse o caso, buscar-se-ia também capacitar e preparar pessoas para um melhor desempenho profissional no setor público. Trata-se de preparar cidadãos para a convivência ativa no âmbito do Estado, ou seja, para uma melhor compreensão dos termos do governo democrático, do desenvolvimento econômico e social, da organização da sociedade civil e do controle social. $\mathrm{O}$ autor acredita que o espectro dos empreendimentos desse tipo pode ser bastante elástico, aparecendo tanto na forma de um maior empenho na organização de atividades de formação de quadros no interior dos partidos políticos, quanto na forma de empreendimentos societais preocupados em preparar pessoal qualificado, em termos técnicos e ético-políticos para exercer funções governamentais nas diferentes esferas da vida social.

As organizações não governamentais que ofertam capacitação diferenciam-se fundamentalmente pelos espaços de atuação e pelas formas de financiamento, fatores que influenciam em seus objetivos e interesses. Algumas instituições destacam-se nesse cenário por, também, promoverem consultoria, assessoria e suporte à realização de concursos públicos. São exemplos o Instituto Brasileiro de Administração Municipal (IBAM) e a Fundação Konrad Adenauer, entre outros.

De maneira geral, esse tipo de organização atua em caráter complementar e concorrente às atividades desenvolvidas pelos órgãos do Estado na oferta de atividades educacionais para servidores e agentes públicos, atendendo demandas de capacitação que o setor público não consegue acolher. Além disso, realizam consultorias nos assuntos em que se tornam especialistas, promovem estudos sobre 
assuntos diversos de gestão pública e até mesmo sobre as escolas de governo, entre outras atividades. As escolas de governo inseridas no aparato estatal podem atuar em parceria ou contratando os serviços das organizações não governamentais, tendo em vista que o caráter dessas organizações pode ser com ou sem fins lucrativos.

\section{Fundações partidárias}

Os institutos ou fundações partidárias são vinculados a partidos políticos, de forma direta ou indireta, e promovem atividades de educação, formação e doutrinação política. Representam um importante locus de formação de quadros para o setor público, principalmente porque é nesses espaços que ocorre a qualificação dos dirigentes políticos e maior qualificação da participação política de diversos atores. No Brasil, a Lei Orgânica dos Partidos Políticos (BRASIL, 1995b) assegura aos partidos autonomia para definir sua estrutura interna, sua organização e seu funcionamento, porém deixa implícita a necessidade de criação de Fundações voltadas à doutrinação dos ideais partidários.

Segundo Prado (2009), as fundações partidárias nasceram da necessidade do envolvimento com a sociedade civil em geral, da participação em debates de temas contemporâneos, de estudos acadêmicos e, principalmente, em quebrar os obstáculos que os partidos políticos possuem no que concerne à aceitação pelos diferentes segmentos da sociedade. O foco principal de atuação não trata da relação entre educação e política, realizada por meio de disciplinas em sala de aula, mas da formação política, voltada àqueles que assumiram cargos eletivos e fazem da política a sua forma de ação. De acordo com Fernandes e Dantas (2012), o viés ideológico de cada fundação está atrelado ao posicionamento que seu mantenedor respira. A conexão entre o partido e a fundação pode ser formal, quando há um vínculo jurídico que conecta a administração do partido com a administração da fundação, ou informal, quando a fundação, ainda que pautada e orientada pela doutrina do partido político, possui uma administração própria e independente da administração partidária.

As ações de formação e educação política foram, aos poucos, sendo inseridas no ordenamento jurídico brasileiro. A Lei Orgânica dos Partidos Políticos de 1971 (BRASIL, 1971) não vislumbrava as ações de ensino como função precípua destas entidades, no entanto, em 1976, foi publicada a Lei no 6.339 (BRASIL, 1976), incluindo a obrigatoriedade da criação de institutos junto aos partidos, destinados à formação, renovação e aperfeiçoamento de quadros e lideranças partidárias. A partir da edição da Lei Orgânica dos Partidos de 1995 (BRASIL, 1995b), foi estabelecida uma nova perspectiva para a atuação das fundações partidárias. 
Artigo 53 - A fundação ou instituto de direito privado, criado por partido político, destinado ao estudo e pesquisa, à doutrinação e à educação política, rege-se pelas normas da lei civil e tem autonomia para contratar com instituições públicas ou privadas, prestar serviços e manter estabelecimentos de acordo com suas finalidades, podendo, ainda, manter intercâmbio com instituições não-nacionais (BRASIL, 1995b).

Outro marco legal foi a edição da Resolução $n^{\circ} 22.121$, de $1^{\circ}$ de dezembro de 2005, do Tribunal Superior Eleitoral (TSE) (BRASIL, 2005), que dispôs sobre as regras de adequação de institutos ou fundações de pesquisa e de doutrinação e educação política de partidos políticos às normas estabelecidas no Código Civil de 2002. Desse modo, os entes anteriormente criados sob a forma de instituto, associação ou sociedade civil deveriam, a partir de então, ser convertidos em fundações de direito privado, nos termos e prazos da lei civil. A resolução do TSE refletiu uma demanda por parte dos partidos políticos no tocante a um maior reconhecimento das fundações, requerendo uma diferenciação legal dessas em relação às demais instituições presentes no Código Civil (PRAdo, 2009; FernANDES; DANTAS, 2012).

A partir de 2009, uma alteração no artigo $n^{\circ} 44$ da Lei Orgânica dos Partidos previu a destinação de recursos financeiros para o funcionamento das Fundações.

Art. 44. Os recursos oriundos do Fundo Partidário serão aplicados:

$[\ldots]$

IV - na criação e manutenção de instituto ou fundação de pesquisa e doutrinação e educação política, sendo esta aplicação de, no mínimo, vinte por cento do total recebido (BRASIL, 2009).

O aporte financeiro destinado às fundações partidárias é proveniente do fundo partidário, distribuído por meio do método referente à força eleitoral e à representação parlamentar que cada partido político possui no Congresso Nacional. Como a divisão dos recursos guarda relação com a expressividade das legendas na Câmara dos Deputados, é esperado que os maiores partidos tenham mais recursos. O controle da aplicação destes recursos cabe ao Ministério Público e, à Justiça Eleitoral, cabe verificar se os partidos repassam os $20 \%$ para as fundações partidárias. A fundação única de cada partido deve ter caráter nacional, havendo, contudo, representações nacionais, estaduais e municipais que recebem recursos de acordo com a divisão proposta internamente (PRADO, 2009; FERNANDES; DANTAS, 2012).

A literatura envolvendo o tema é escassa, não havendo estudos sobre como atuam e quais atividades promovem esses órgãos. Devido ao grande desconhecimento sobre as fundações partidárias, Fernandes e Dantas (2012) questionam se, de fato, suas ações estão sendo utilizadas como instrumentos de educação política e aprofundamento dos valores democráticos, ou se estão sendo destinadas a 
fins outros e não condizentes com aquilo que se espera de sua atuação. Surgem, assim, críticas relacionadas a supostos desvios de finalidade de suas atividades e ausência da fiscalização na utilização dos recursos a elas destinados. De acordo com Franco (2011), a maior parte das fundações não tem sede própria, usa os recursos com pouca transparência e entrega sua gestão a políticos sem mandato. Sendo institutos relacionados à educação política, Dantas (2010) analisa que nenhuma das fundações partidárias brasileiras possui programas abrangentes relacionados à sua função precípua, que tem o propósito de fortalecer aspectos centrais da essência de cada partido, de colocar o cidadão em contato com os partidos, levá-lo a escolher de forma racional o discurso, o programa e o projeto que melhor se adequa às suas concepções de realidade, bem-estar e, sobretudo, de consolidação de direitos sob o formato de políticas públicas. Em geral, são feitos apenas programas de formação complementar para militantes e para gestores, não havendo um esforço sistematizado de formação política para a juventude, convênio com programas de pós-graduação, bolsas de estudo ou cursos que incluam a interação com lideranças partidárias. Conclui Dantas (2010) que os institutos partidários possuem diferentes graus de institucionalização e desenvolvimento de sua capacidade de produzir pesquisa, divulgar seu credo e valores políticos e de investir na formação política de quadros e militantes do partido.

Todos os partidos políticos são obrigados a encaminhar ao Tribunal Superior Eleitoral $^{6}$ o nome da fundação de pesquisa, doutrinação e educação política, a indicação do seu representante legal, número de inscrição no CNPJ, endereço da sede, telefone, e-mail e fac-símile. As fundações partidárias expandiram-se com objetivos legalmente definidos, mas com falta de transparência na utilização dos recursos a elas destinados. Enquanto há um aumento quantitativo e qualitativo dos demais modelos de profissionalização para o setor público, a atuação das fundações partidárias na formação política ainda é pouco conhecida, mesmo que venha ocorrendo maior pressão para melhorar e qualificar a atuação dos agentes políticos. Estes órgãos são relevantes para promover a qualificação dos dirigentes políticos e pela melhoria da participação política da sociedade.

\section{Considerações finais}

Com a intenção de compreender os diversos modelos de escolas de governo instituídos no Brasil, constatamos que existem diversas experiências de profissionalização de servidores públicos, as quais são viabilizadas por uma

\footnotetext{
${ }^{6}$ Conforme previsão do artigo 40 da Resolução TSE no 23.282, de 22/06/2010, que disciplina a criação, organização, fusão, incorporação e extinção de partidos políticos.
} 
multiplicidade de organizações, situadas em espaços diversificados, atendendo a um público amplo e heterogêneo. Partindo do pressuposto de que a melhoria da gestão pública não depende somente da atuação do aparato governamental, ações de capacitação devem estar permeadas na oferta de variados serviços públicos, estatais ou não. Assim, a atuação de um único modelo de capacitação e formação é insuficiente para o atendimento das demandas de qualificação para o setor público. Em cada ambiente, encontram-se diferentes tipos de formação, os quais devem assumir sua parcela de responsabilidade e atuar em parceria com outros modelos, fornecendo capacitações que agreguem conhecimento aos diversos atores envolvidos. A realização de parcerias é o caminho a ser trilhado para a superação do isolamento institucional das instituições e enfrentamento dos desafios da sociedade.

A profissionalização para o setor público apresentou-se como um objetivo comum entre os modelos pesquisados. O traço mais marcante esteve relacionado à heterogeneidade, tendo em vista a variedade de espaços em que se inserem, a diversidade de destinatários, os objetivos perseguidos e a amplitude de formas de atuação. A análise do ambiente em que se estabeleceram permitiu-nos perceber que os diversos modelos foram desenvolvendo-se paralelamente ao longo da história político-administrativa brasileira, porém com poucas intersecções significativas. O cenário que vem se desenhando propicia uma maior integração entre a oferta formativa para o setor público, o que demandará, em um futuro próximo, a coordenação estruturada e formalizada de ações, a realização efetiva de parcerias e a utilização de mecanismos institucionais que agreguem as diversas propostas.

Diante de vantajosas possibilidades também se encontram alguns desafios. À medida que um modelo não atenda a contento suas demandas, abre-se uma lacuna para que outros modelos atuem de forma concorrente na oferta de cursos. No entanto, os cursos ofertados nem sempre estão alinhados às demandas apresentadas, não atendendo às necessidades da organização demandante e gerando frustração nos participantes. Os cursos adquiridos nas instituições externas, muitas vezes, não são adequados em termos de conteúdos, metodologias e, principalmente, ideologias e valores. Além disso, limitações relativas ao orçamento e infraestrutura podem ser fatores impeditivos da expansão de ações voltadas à profissionalização de agentes públicos. Ainda faz-se necessário superar a lógica de que as atividades educativas no setor público são vistas como gastos e não como investimentos.

As ações de capacitação e formação para o setor público somente geram resultados caso estejam efetivamente vinculadas às demandas identificadas, capazes de diminuir as lacunas de qualificação e promover melhorias no desempenho individual e organizacional. Pensar em uma escola de governo, ou qualquer outro modelo de profissionalização para o setor público, somente faz sentido se 
essas unidades estiverem vinculadas ao atendimento de projetos democráticos e de garantia de direitos. As atuações dos diferentes modelos apresentados neste artigo estão cada vez mais se interpenetrando e, além disso, vêm sendo realizadas, muitas vezes, ações conjuntas. Aos agentes públicos estão disponíveis amplas possibilidades de capacitação, tendo em vista que a formação e atuação voltadas ao setor público não se restringem somente a uma única organização. A superação dos desafios da gestão pública brasileira perpassa a compreensão e desenvolvimento dos modelos de profissionalização de servidores públicos, capazes de viabilizar maior capacidade de governo nas diversas organizações e promover a melhoria na prestação de serviços.

\section{Referências bibliográficas}

AlPERSTEDT, Cristiane. Universidades corporativas: discussão e proposta de uma definição. RAC - Revista de Administração Contemporânea. Curitiba: Anpad, v. 5, n. 3, p. 149-165, set-dez, 2001.

AzEVEDo, Clóvis Bueno. Escolas de governo e carreiras públicas: efetivamente públicas e de governo? In: CARNEIRO, José Mário Brasiliense; AMORIM, Alexandre (Orgs). Escolas de Governo e gestão municipal. São Paulo: Oficina Municipal, 2003. p. 37-54.

BRASIL. Presidência da República. Lei no 5.682, de 21 de julho de 1971. Lei Orgânica dos Partidos Políticos. Brasília, 1971.

Presidência da República. Lei no 6.339, de 1o de julho de 1976. Dá nova redação ao artigo 250 da Lei no 4.737, de 15 de julho de 1965, alterado pelo artigo 50, da Lei no 4.961, de 4 de maio de 1966, e ao artigo 118 da Lei no 5.682, de 21 de julho de 1971. Brasília, 1976.

Senado Federal. Constituição: República Federativa do Brasil. Brasília, 1988.

Senado Federal. Projeto de Emenda Constitucional no 173, de 1995. Brasília, 1995a.

Presidência da República. Lei no 9.096, de 19 de setembro de 1995. Dispõe sobre partidos políticos, regulamenta os arts. 17 e $14, \S 30$, inciso V, da Constituição Federal. Brasília, 1995b.

Senado Federal. Emenda Constitucional no 19 de 1998. Brasília, 1998.

. Tribunal Superior Eleitoral. Resolução TSE no 22.121, de 1ㅇ de dezembro de 2005. Dispõe sobre as regras de adequação de institutos ou fundações de pesquisa e de doutrinação e educação política de partidos políticos às normas estabelecidas no Código Civil de 2002. Brasília, 2005.

Escola Nacional de Administração Pública. ENAP 20 anos: caminhos de uma escola de governo. Brasília: Enap, Cadernos Enap, Ed. Especial, 104p, 2006. 
Presidência da República. Lei $n^{\circ}$ 12.034, de 29 de setembro de 2009. Altera as Leis n 9.096, de 19 de setembro de 1995 - Lei dos Partidos Políticos, 9.504, de 30 de setembro de 1997, que estabelece normas para as eleições, e 4.737, de 15 de julho de 1965 - Código Eleitoral. Brasília, 2009.

Escola Nacional de Administração Pública. Balanço de Gestão: 20112014. Brasília: Enap, 44p, 2014b.

CARvalho, Paulo César de. Escolas de governo e cooperação. In: Congreso INTERNACIONAL DEL CLAD SOBRE LA REFORMA DEL ESTADO Y DE LA ADMINISTRACIÓN PúBLICA. X, 18 - 21 oct. 2005, Santiago, Chile. Anais... Santiago, 2005.

Rede nacional de escolas de governo no brasil: aprendizagens e desafios. In: Congreso INTERNACIONAL DEL CLAD SOBRE LA REFORMA DEL ESTADO Y DE LA AdMinistración PúBliCA. XVII. 30 oct. -2 nov, 2012. Cartagena, Colômbia. Anais... Cartagena, 2012.

CoelHo, Fernando de Souza. Educação superior, formação de administradores e setor público: um estudo sobre o ensino de administração pública - em nível de graduação - no Brasil. 2006. 151 p. Tese (Doutor em Administração Pública e Governo) - Escola de Administração de Empresas de São Paulo, Fundação Getúlio Vargas. São Paulo, 2006.

Coelho, Fernando de Souza; Nicolını, Alexandre Mendes. Como tudo começou? Apontamentos históricos sobre a Implantação do Ensino de Graduação em Administração Pública no Brasil (1952-1965). Revista Temas de Administração Pública. Araraquara: Unesp, ed. especial, v. 2, n. 6, 2011.

DANTAS, Humberto. O caráter essencial da educação política e o desenvolvimento da democracia no Brasil. In: Fundação KonRAd Adenauer. Educação Política: reflexões e práticas democráticas. Cadernos Adenauer. Rio de Janeiro: Fundação Konrad Adenauer, XI, n. 03, 2010.

FARAH, Marta Ferreira Santos. Administração pública e políticas públicas. RAP Revista de Administração Pública. Rio de Janeiro: FGV, v.45, n.3, p. 813-36, maio/ jun, 2011.

Fernandes, Ciro Campos Christo. O tema das escolas de governo na emenda da reforma administrativa. Respvblica. Brasília: ANESP, v. 12, n. 2, jul-dez, 2013.

FERNANDES, Ivan Filipe de Almeida; DANTAS, Humberto. Fundações partidárias no Brasil e no mundo: funções legais, ações formativas e análise em perspectiva comparada. 2012. (Apresentação de Trabalho/Outra). Disponível em: <http://www. cienciapolitica.org.br/wp-content/uploads/2014/04/3_7_2012_15_25_10.pdf.>. Acesso em: 08 dez/2014.

FrANCO, Bernardo Mello. Repasses para fundações partidárias crescem $50 \%$. Folha de São Paulo, São Paulo, 22 jan. 2011. Poder. Disponível em: <http://www1.folha. uol.com.br/poder/864398-repasses-para-fundacoes-partidarias-crescem-50. shtml>. Acesso em: $08 \mathrm{dez} / 2014$.

GAETANI, Francisco. Capacitação de recursos humanos no serviço público: problemas e impasses. Brasília: Enap, Texto para discussão, p.27, 1998. 
O ensino de administração pública no Brasil em um momento de inflexão. RSP - Revista do Serviço Público. Brasília: Enap, ano 50, n. 4, out-dez 1999. MACK, Bruno Scott. A implantação de uma universidade corporativa no setor público: o estudo de caso da Escola de Contas e Gestão do Tribunal de Contas do Estado do Rio de Janeiro. 2008. 165p. Dissertação (Mestre em Administração Pública) - Escola Brasileira de Administração Pública e de Empresas, Fundação Getúlio Vargas. Rio de Janeiro, 2008.

Matos, Fabiana Oliveira. Escolas de governo na Constituição Federal: a regulamentação no âmbito da Administração Pública Federal. 2007.46p. Monografia (Especialização) - Instituto Brasiliense de Direito Público. Brasília, 2007.

MATUs, Carlos. Proyecto: Escuela Latinoamericana de Gobierno (ESCOLAG). [S.I] (versión revisada, julio de 1995). Mimeo, 1995.

Adeus, Senhor Presidente: governantes, governados. São Paulo: Fundap, 1997.

Triângulo de Governo. [S.I.]: Strategia Consultores Ltda. Fundación Altadir, 2006.

Escuela de Gobierno. Salud Colectiva. Buenos Aires: [s.n.], 2007b, 3(2): 203-212, mai-ago, 2007.

MEISTER, Jeanne C. Educação Corporativa. Tradução: Maria Claudia Santos Ribeiro Ratto. São Paulo: Makron Books, 1999

Nicolini, Alexandre Mendes. Qual será o futuro da fábrica de administradores? Revista de Administração de Empresas, São Paulo: RAE, v. 43, n. 2, p. 44-54, abr-jun. 2003. Disponível em: <http://rae.fgv.br/rae/vol43-num2-2003/qual-sera-futurofabricas-administradores>. Acesso em: 10 set. 2014.

Nogueira, Marco Aurélio. Atualidade, força e sentido das escolas de governo. In: Um Estado para a sociedade civil: temas éticos e políticos da gestão democrática. São Paulo: Cortez, p. 167-193, 2005.

PACHECO, Regina Sílvia. Escolas de governo: tendências e desafios - ENAP-Brasil em perspectiva comparada. RSP - Revista do Serviço Público. Brasília: Enap, ano 51, n. 2, p. 03-21, 2000.

Escolas de governo como centros de excelência em gestão pública: a perspectiva da ENAP - Brasil. RSP - Revista do Serviço Público. Brasília: Enap, ano 53, n. 1, p. 75-86, jan-mar, 2002.

Escolas de governo: evolução histórica e perspectivas para os municípios. In: CARNEIRO, José Mário Brasiliense; AMORIM, Alexandre (Orgs). Escolas de Governo e Gestão Municipal. São Paulo: Oficina Municipal, p.19-35, 2003.

PIRES, Valdemir et al. Dossiê campo de públicas no Brasil - definição, movimento constitutivo e desafios atuais. Revista APGS - Administração Pública e Gestão Social. [S.I., s.n.] v.6, n.3, jul-set 2014. p. 110-126.

PRADO, Henrique Sartori de Almeida. El papel de las fundaciones de los partidos políticos en el desarrollo de la democracia brasileña. Libel - The International Federation of Liberal Youth Organization Magazine, p. 1-6, 27 abr. 2009. 
RAMOS, David Ricardo Moreira. Universidades corporativas: possibilidades e dificuldades de sua implantação - estudo de casos. 2001. 135p. Dissertação (Mestrado em Administração Pública) da Escola Brasileira de Administração Pública e de Empresas da Fundação Getúlio Vargas. Rio de Janeiro: FGV, 2001.

RouAnet, Sérgio Paulo. Criação no Brasil de uma escola superior de administração pública. Brasília: Enap, 2005. p. 96.

SANTOS, Maria Helena de Castro et al. As experiências nacionais no campo da profissionalização. IN: PetrucCI, Lucia; BRIto, Marcelo; SANTOS, Maria Helena de Castro (Coords) (1995). Escolas de governo e profissionalização do funcionalismo. Brasília: Enap/CDID, 1995.

ZAVATTI, Waleska Yone Yamakawa; BALduíno, Maria Aparecida Canale. Educação corporativa no setor público: um estudo sobre o Tribunal de Contas do Estado de Goiás. 2013. Monografia (Especialista) - convênio UCDB - Universidade Católica Dom Bosco e Portal Educação. Goiânia, 2013.

Milena de Senne Ranzini

Possui mestrado em Educação pela Universidade Estadual de Campinas (Unicamp). Atualmente é Analista de Gestão de Pessoas da Prefeitura Municipal de Campinas/SP. Contato: miranzini@yahoo.com.br 